\title{
Article \\ The Reattachment Process of a Lifted Jet Diffusion Flame by Repetitive DC Pulse Discharges
}

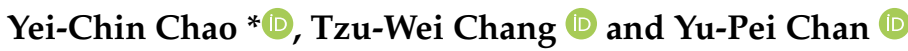 \\ Department of Aeronautics and Astronautics, National Cheng Kung University, Tainan 701, Taiwan; \\ a911049@ms66.hinet.net (T.-W.C.); z10812022@ncku.edu.tw (Y.-P.C.) \\ * Correspondence: ycchao@mail.ncku.edu.tw; Tel.: +886-62-757-5756-3690
}

Citation: Chao, Y.-C.; Chang, T.-W.; Chan, Y.-P. The Reattachment Process of a Lifted Jet Diffusion Flame by Repetitive DC Pulse Discharges. Processes 2021, 9, 534. https:// doi.org/10.3390/pr9030534

Academic Editor: Alfredo Iranzo

Received: 7 January 2021

Accepted: 12 March 2021

Published: 17 March 2021

Publisher's Note: MDPI stays neutral with regard to jurisdictional claims in published maps and institutional affiliations.

Copyright: (c) 2021 by the authors. Licensee MDPI, Basel, Switzerland. This article is an open access article distributed under the terms and conditions of the Creative Commons Attribution (CC BY) license (https:/ / creativecommons.org/licenses/by/ $4.0 /)$.

\begin{abstract}
On research of plasma assisted combustion, effects of electric and plasma discharges in DC, $\mathrm{AC}$ and pulse forms on reattachment of a lifted flame have attracted extensive attention. However, the detailed plasma assisted reattachment process and mechanism and roles of induced corona discharge and corona-induced ozone on the reattachment process are still unclear and undocumented. The forced reattachment process of a lifted diffusion jet flame by repetitive DC electric pulse discharges was experimentally investigated in this study using high-speed flame imaging, conditioned particle image velocimetry (PIV), and planar ozone concentration imaging. The forced reattachment process can be divided into three stages in sequence: ionic wind prior to corona initiation, corona initiation, and corona enhancement propagation. The conditioned PIV results showed that the instantaneous flame base propagation velocity is sufficiently enhanced beyond the laminar burning velocity for high pulse-repetition-frequency (PRF) cases at the instant of pulse discharge (on pulse) due to the enhanced oxidation of the corona induced ozone. By observing the dynamic flame-base behavior and evolution characteristics of the short-lived corona induced ozone for various PRFs, the novel forced reattachment process and mechanism of a lifted jet flame induced by repetitive DC electric pulse discharges is proposed.
\end{abstract}

Keywords: flame reattachment; electric pulse discharge; lift off flame; flame propagation

\section{Introduction}

Although fuel lean combustion of low carbon-content fuel can provide high energy efficiency and emit low carbon pollution, it generally produces NOx emission. By controlling the quantity of injected fuel as opposed to throttling the air volume, the low-temperature combustion can be obtained with accurate control of injection time, leading to the low NOx emissions. Nevertheless, lean combustion process has its inherent problem of flame instability, which leads to unstable flame behaviors such as liftoff and blowout in nonpremixed jet flame and unstable extinction in premixed jet flame, resulting in leakage of unburned fuel and safety issues. Hence, the combustion enhancement by electric and plasma discharges has attracted intensive research attention and has been demonstrated as a promising approach to effectively improve the combustion performance by altering the fundamental combustion behaviors, such as burner flame stability [1], burning velocity [2], and emission reduction [3]. The effects on combustion process are mainly through three enhancement pathways, namely thermal heating, kinetic, and hydrodynamic enhancements. Firstly, plasma can rapidly raise the mixture temperature via energy transfer from electrons to molecules. The second enhancement pathway is that high energy electrons, ions, and molecules produced from plasma lead to the subsequent production of active radicals and reactive species in the fuel and air streams. Plasma generated ionic wind and flow motion via the Coulomb and Lorentz forces provides hydrodynamic enhancement by changing local velocity [4]. In general, since these effects are coupled to combustion system, it is difficult to isolate them and clearly describe the progressive mechanisms individually. 
The electron energy is mainly dominated by the reduced electric field intensity relative to the gas density, $E / N$, where $E$ is electric field intensity between the electrodes and $N$ is the total gas number density which is in ideal gas related to gas pressure. At low $E / N$ field, the electron energy is insufficient to produce the excited species. Nevertheless, these electrons can redistribute their momentum to the neutral atoms and molecules in the external electric field. Comparing with alternative current (AC) electric field, directive current (DC) electric field has insignificant effect on flame stabilization with either positive or negative polarity. To increase the current flowing through the flame, a two-electrode configuration was used to augment the coupled effect of DC electric field on the flame-edge. The resultant modifications on the flame/flow behaviors in the premixed jet flame [5] and the lifted flame base [6] were delineated based on the ion-driven-wind (ionic wind) model. On the other hand, at the higher $E / N$ field, the electrons can directly induce the production of ions, high-level excited species, and chemically active species during the electrical pulse to form a self-sustained plasma discharge [7]. A variety of electric nonequilibrium plasma discharges have been examined and demonstrated the beneficial effects on increasing blowoff velocity of premixed hydrocarbon flames [8,9] and on the reduction of flame liftoff height and extension of flame stabilization regime for a lifted methane jet diffusion flame [10-12]. In addition, the reattachment phenomenon appearing in a bluff-body stabilized, lean propane-air flame with a nanosecond pulse repetitive discharge (NPRD) at the repetition rate of $10 \mathrm{kHz}$ was reported [9] and the positive pulse corona (streamer) discharge was identified when the reattached flame came close to the electrode. In general, in atmospheric air the positive pulse corona (streamer) discharge can produce $\mathrm{O}_{3}$ more effectively than that of dielectric-barrier discharge (DBD) system, and its electric energy is mostly transferred to chemical energy without significant heating of gas [13]. The investigation of adding plasma-produced ozone molecules to hydrocarbon flames also has been motivated [14]. The enhancement in flame propagation speed of propane lifted jet flame by ozone addition was confirmed experimentally by Ombrello et al. [15]. Chang et al. [16] tried to investigate the electric/plasma forced reattachment process of a lifted diffusion flame by using high-speed camera and cond-particle image velocimetry (PIV) (PIV measurement conditioned with respect to "instantaneous" flame position and velocity using high-speed camera simultaneously) and results of cond-PIV showed that the flame propagation speed can be above $3 S_{L}$ (laminar flame velocity), an "exceptional" high reattaching flame velocity, when corona is induced with high pulse repetition frequency (PRF). However, the results were not very successful and were not satisfactory as the electric/plasma forced flame reattachment is not a steady, axisymmetric process and the 2D planar PIV using laser sheet tends to miss to capture the flame location and the leading flame base point of the reattaching flame. In addition, the velocity measurements cannot fully explain the complicated electric/plasma-flame interaction and cannot delineate the interaction mechanism, in which the induced chemical interaction, such as induced Ozone, may involve and contribute to the reattachment process.

Although the electric/plasma assisted combustion enhancement phenomena [1-7], especially on the reattachment enhancement of a lifted flame [8-12,15], are interesting and may be of paramount importance to practical application on flame stabilization, the detailed plasma assisted reattachment process and mechanism, and the role of induced corona discharge and the role of corona-induced ozone on the enhancement of the reattachment process, are still unclear and undocumented. Accordingly, the present study is focused on the enhanced reattachment behaviors and forced propagation process of a lifted nonpremixed propane jet flame by repetitive pulsed DC discharges. The focus and the novelty of this experimental study is that based on previous cond-PIV results [16]; further in-situ laser measurements using 2D line-of-sight laser absorption technique for induced ozone concentration are applied to investigate the electric/plasma forced reattachment process and mechanism. The effect of various pulse repetition frequencies (PRFs) and diverse voltage polarity are also examined experimentally to clarify the enhanced reattachment process and mechanism. 


\section{Materials and Methods}

\subsection{Burner and Electric Corona Discharge Configurations}

The arrangement of the propane jet burner and the discharge electrode for the experiments are schematically shown in Figure 1 . The jet burner is made of a straight circular quartz-tube, $3 \mathrm{~mm}$ in inner diameter with a length-to-diameter ratio of 150 to ensure fully developed pipe flow at exit. In the experiment, a diffusion flame was presented, and the volumetric flow rate of fuel and air were determined from the rotameter to evaluate the bulk jet exit velocity, Ve. The investigated Ve ranged from $4 \mathrm{~m} / \mathrm{s}$ to $12 \mathrm{~m} / \mathrm{s}$, corresponding to the Reynolds number, $\operatorname{Re}=2600 \sim 7800$. The single-electrode configuration was chosen as the electric discharge setup. The configuration consisted of a thin brass cylinder with a sharp tip as the discharge electrode, which was connected to the high-voltage DC pulse generator with switchable polarity, and the lifted-flame reaction zone served as a virtual ground electrode. The electrode location was fixed at $R=4.5 \mathrm{~mm}(1.5 \mathrm{D})$ and $Z=0 \mathrm{~mm}$ with respect to burner exit center $(R=0 \mathrm{~mm}, Z=0 \mathrm{~mm})$ in all test cases. Electrode was detached from the burner rim to distinguish the outstanding effect of electric/plasma on the "enhancement/assistance" of the flame reattachment process and chosen to locate at a radial position below the lifted flame base close to flow shear layer of the fuel jet where it is easy to initiate corona discharge. Because corona discharge is cold plasma at atmospheric pressure, heat transfer to gas is slow, which would not significantly raise gas temperature. The DC high-voltage pulse generator could generate single pulse voltage with a pulse duration of $80 \mu$ s and a peak value of $\pm 16 \mathrm{kV}$, and it was triggered by a pulse delay generator unit at different pulse repetition frequencies (PRFs) ranged from $100 \mathrm{~Hz}$ to $1500 \mathrm{~Hz}$. The instantaneous voltage and current applied to the electrode were measured simultaneously by a high voltage probe (Tektronix, P6015A, Beaverton, OR, USA) and a Rogowski Coil (Pearson Electronics, MODEL-150, Palo Alto, CA, USA). Each pulse shape and discharge power were monitored and recorded throughout the experiments.

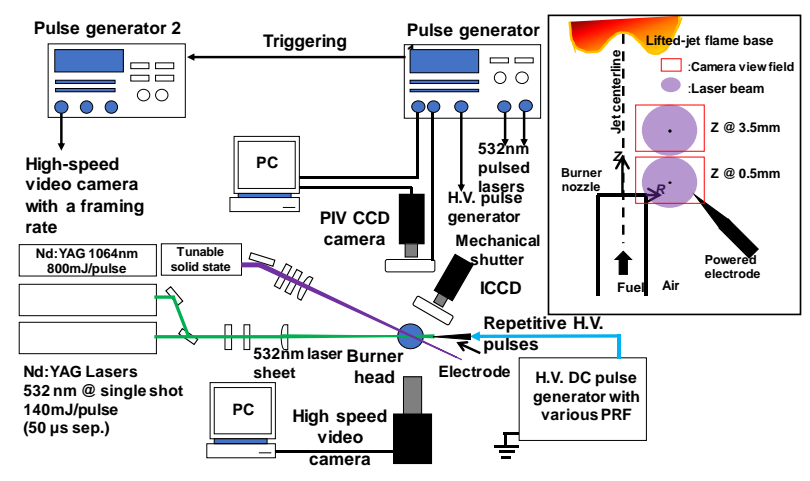

Figure 1. Schematic of the experimental setup and optical measurement arrangement.

\subsection{Conditional Flame-Edge Propagation Speed Measurement}

To study the dynamic flame response to pulse discharges applied with various PRFs, the instantaneous measurements of flame base locations varied with time and the corresponding local gas velocity field near flame base were conducted. For a lifted jet flame, the instantaneous lift-off height, $H_{b}$, is defined as the axial distance between the most upstream flame-base location (leading-edge) and nozzle exit. The flame-base location was determined by high-speed image, and in contrast to the axisymmetric flame base usually found in natural flame reattachment, in the present single-electrode setup the electric/plasma forced flame reattachment occurs on one side with a sharp pointing flame base as can be seen from the flame picture. Therefore, the high-speed camera can capture the real flame base of the present forced flame reattachment. The instantaneous flame propagation speed at the leading-edge, $S e$, relative to upstream unburned mixture could be estimated by Se $=V_{g}+V_{F}$, where $V_{g}$ and $V_{F}$ are respectively the axial component of instantaneous gas velocity and the corresponding lab-coordinate absolute flame speed. The corresponding lab-coordinate absolute flame speed can be calculated from high-speed camera images. To 
accurately determine the gas velocity relative to a rapid-moving flame base, simultaneously employing a shuttered particle image velocimetry (PIV) system conditioned with respect to instantaneous flame base location using a high-speed camera is indispensable. The detailed description of the conditioned PIV (cond-PIV) measurement technique can be referred to a previous article [16]. The flame-base location was determined by high-speed image, and in contrast to the axisymmetric flame base usually found in natural flame reattachment, in the present single-electrode setup the electric/plasma forced flame reattachment occurs on one side with a sharp pointing flame base as can be seen from the flame picture. Therefore, the high-speed camera can capture the real flame base of the present forced flame reattachment.

In this experiment, shuttered PIV system consisted of two pulse Nd:YAG lasers with pulse duration of $7 \mathrm{~ns}$ at $532 \mathrm{~nm}$, a $1360 \times 1024$-pixel high-sensitivity charge-coupled device (CCD) camera (Pixelfly, 220XD, Kelheim, Germany), a mechanical shutter in front of CCD camera, and $\mathrm{Al}_{2} \mathrm{O}_{3}$ seeding particles of $1 \mu \mathrm{m}$ diameter. $\mathrm{Al}_{2} \mathrm{O}_{3}$ particles were chosen because it would not react when passing through flame zone. The cond-PIV measurement was separated into the on-pulse and the interpulse period by using two pulse delay generators. For on-pulse measurement, the first and second PIV laser pulses were respectively triggered at $35 \mu \mathrm{s}$ and $85 \mu \mathrm{s}$ following the initiation of electric pulse and the interpulse was triggered in the middle between two neighboring electric pulses for the two typical cases studied. The PIV scattering images are captured on a progressive interline transfer CCD camera $(1360 \times 1024$ pixels) equipped with double-exposure function. The image of the camera is found to be $28 \mu \mathrm{m} /$ pixel in a field of view of $29.5 \times 38.9 \mathrm{~mm}^{2}$ imaged by a $75 \mathrm{~mm}$ lens. The interrogation window size and overlap were respectively $16 \times 16$ pixels and $62 \%$, and it corresponds to a PIV spatial resolution as smaller as $0.17 \mathrm{~mm}$, which is considered to be sufficient for the present study. On the other hand, the temporal resolution for flame base velocity was limited to maxi-mum framing rate of high-speed video camera whose frame rating was $1250 \mathrm{~Hz}$. A conservative estimate of the uncertainty in absolute flame speed is within $0.05 \mathrm{~m} / \mathrm{s}$.

\subsection{Average 2D Ozone Density Measurement and Analysis}

To identify the role of induced ozone on the enhancement of the reattachment velocity of a lifted flame leading to the re-stabilization of the lifted flame onto the burner exit, the planar ozone absorption technique $[17,18]$ was adopted. However, due to the short-lived and weak absorption intensity nature of the induced ozone, shot-to-shot quantitative data comparison is infeasible. Instead, the ozone image relative to unpulsed background is used to qualitatively delineate the forced reattachment phenomena and process. The qualitative spatial and temporal distributions of $\mathrm{O}_{3}$ density was measured by using twodimensional UV absorption method. The experimental apparatus is shown in Figure 1. A 1064-nm Nd: YAG pulse laser was used to pump the two external frequency modulators to excite an adjustable fundamental wavelength to $744 \mathrm{~nm}$ and then, to the third harmonic wavelength of $248 \mathrm{~nm}$ with a $15 \mathrm{~ns}$ pulse duration. The laser beam was introduced into the space around the electrode tip, and its cross section was enlarged with a set of optical lenses to a $3 \mathrm{~mm}$-diameter circular space. By expanding the laser beam for the ozone measurements, it is a line-of-sight measurement and a spatially integrated information is obtained. The intensified charge-coupled device (ICCD) camera (Princeton Instruments PI-MAX3, Trenton, NJ and Acton, MA, USA) was synchronously triggered to capture the fluorescence of projected beam pattern. The recorded images were compared with that of a reference case, a beam pattern without electric discharge, to determine the beam absorption ratio for each image pixel.

According to Beer-Lambert law, described as the absorbance, $A$, being proportional to the absorbing material concentration, $C$, in mole per liter and the path length in the absorption medium, $L$, in centimeter. It can be represented by the relation:

$$
A=\kappa \times C \times L=-\ln \frac{I}{I_{0}}
$$


where $I$ is the intensity of transmitted light, $I_{0}$ the intensity of incident light, $\kappa$ the molar absorption coefficient of material for the specific wavelength of incident light, which has a relation with the absorption cross section, $\sigma$, and number density of ozone can be expressed as:

$$
\mathrm{N}_{\text {ozone }}=\frac{-\ln \frac{I}{I_{0}}}{\sigma \times L}
$$

\section{Results and Discussions}

This section may be divided by subheadings. It should provide a concise and precise description of the experimental results, their interpretation, as well as the experimental conclusions that can be drawn.

\subsection{Effect of Pulse Repetitive Frequency}

The variation of mean liftoff heights with PRF for various $V e$ cases is shown in Figure 2, which is to compare with the data obtained from natural lifted jet flame without pulsed discharges $(\mathrm{PRF}=0 \mathrm{~Hz}$ ) represented by the hollowed symbols. It is apparent that the mean liftoff height decreased with increasing PRF for all the Ve cases under positive and negative polarity of applied voltage. For positive polarity cases, the mean liftoff height reduces significantly as increasing PRF from $100 \mathrm{~Hz}$ to $1500 \mathrm{~Hz}$, especially in the lower Ve cases, and the reattachment would occur at different critical $P R F$ for $V e$ of $7 \mathrm{~m} / \mathrm{s}$ to $12 \mathrm{~m} / \mathrm{s}$ cases. In other words, the effect of each applied PRF has its limitation in Ve case. In negative polarity conditions, the enhancement in reducing mean liftoff height is insignificant compared to that of positive polarity condition, and the mean liftoff heights for most Ve cases seemed to reach gradually a constant height of about $6.5 \mathrm{~mm}$ at PRF of $1500 \mathrm{~Hz}$, except for $V e$ of $7 \mathrm{~m} / \mathrm{s}$ case, for which the reattachment occur successfully at PRF of $1250 \mathrm{~Hz}$. It suggests that the PRF is a key parameter and has shown positive effect on lifted-flame stabilization with positive polarity of voltage pulses.

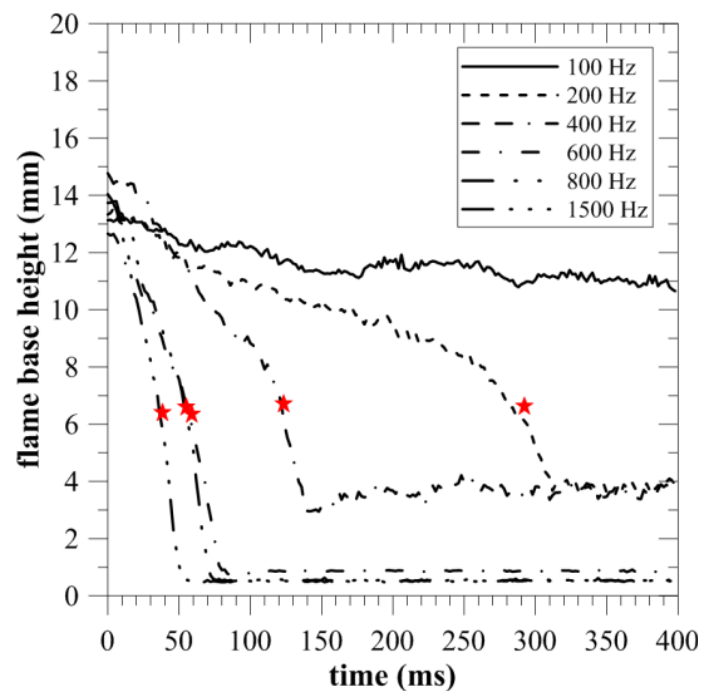

Figure 2. Temporal evolution of flame base height during forced propagation process for various pulse-repetition-frequency (PRF) cases. The red stars represent the moment appearing the first corona discharge and corresponding transient flame base height.

Figure 3 shows the instantaneous typical flame base images at specific time intervals after initiating repetitive DC positive voltage pulses of peak $16 \mathrm{kV}$ at various $P R F$ s for Ve of $10 \mathrm{~m} / \mathrm{s}$ case. The nozzle is shown in the bottom side of each flame image. The electrode is located at $Z=0 \mathrm{~mm}, R=1.5 \mathrm{D}$, indicated by a sharp white cone in the right side of the image. Red circles near electrodes indicated the appearance of corona discharge as seen of vague white dots. The experimental results can be typically classified according to 
resultant flame-edge type. For $100 \mathrm{~Hz}$ case, the flame base moves slightly upstream and inclines to the electrode side with a slight decrease in liftoff height. As increasing the PRF to $200 \mathrm{~Hz}$, the flame base becomes a slanted ring exhibiting a pointing-edge with a cusp-like shape at about $290 \mathrm{~ms}$ after initiation of pulsed discharges. Moreover, the flame base could propagate upstream to the lower location along the electrode side, and eventually, reattach at the nozzle rim for $P R F$ of 600 and $1500 \mathrm{~Hz}$ cases. It is found that the duration of dynamic propagation process is shorter with an increase in PRF. On the other hand, the fact that the pulsed corona discharges cannot ignite the mixture in the upstream of a lifted flame has been confirmed, whose thermal heating effect is insignificant. Thus, it suggests that flame reattachment is an enhancement propagation process induced by pulsed discharges when the electrode is far from the flame base initially.

(a)
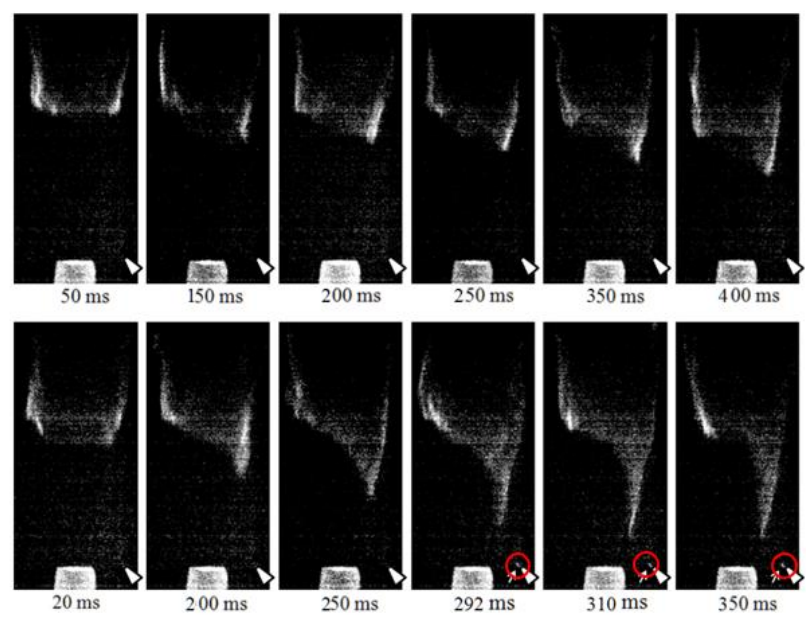

(d)
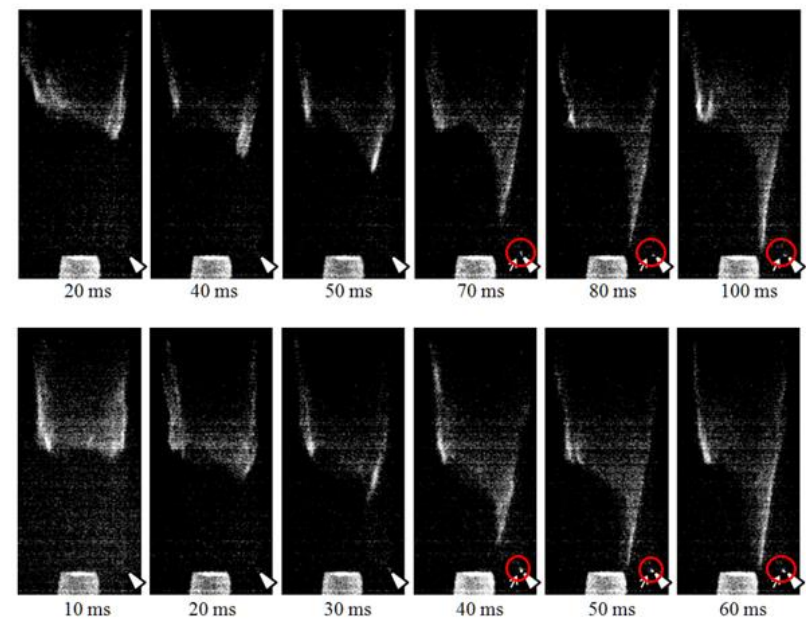

Figure 3. Typical time sequence of instantaneous photographs of propagating flame edge toward nozzle exit when applying repetitive pulsed discharges at various PRF cases: (a) $100 \mathrm{~Hz}$ (b) $200 \mathrm{~Hz}$ (c) $600 \mathrm{~Hz}$ (d) $1500 \mathrm{~Hz}$. The triangle near jet exit indicates the electrode location and the red circle indicates appearance of corona plasma discharge seen as vague white dot near the electrode-tip.

\subsection{The Dynamic Response of Flame Base Motion}

Figure 2 illustrates the time history of ensemble average of liftoff height over the specific time intervals for various $P R F$ cases from the high-speed flame images. The results show that there is a significant difference in flame dynamic behavior with an increase in $P R F$. For low PRF of $100 \mathrm{~Hz}$ case, the liftoff height decreases monotonously to a value of $11 \mathrm{~mm}$ at $400 \mathrm{~ms}$; nonetheless, it reduces sharply to $4 \mathrm{~mm}$ at $320 \mathrm{~ms}$ and $150 \mathrm{~ms}$ for PRF of $200 \mathrm{~Hz}$ and $400 \mathrm{~Hz}$ respectively, and the flame base can anchor stably at these heights. As increasing $P R F$ up to a value higher than $600 \mathrm{~Hz}$, the flame base directly reattaches to the nozzle rim, namely liftoff height is less than $1 \mathrm{~mm}$. The stationary flame-edge is maintained up to $1 \mathrm{~s}$ by continuously applying voltage pulses. In addition, the transient flame base height and the elapsed time, when the initiation of corona discharge for various $P R F$ is identified in the high-speed flame images in each time sequence, can be obtained statistically from the high-speed images and the results are shown in Figure 2 by red stars, except for $100 \mathrm{~Hz}$ case without corona. It is indicated that the flame base height marked by these red stars is approximately $6.5 \mathrm{~mm}$ for the PRF of $200 \mathrm{~Hz}$ to $1500 \mathrm{~Hz}$ cases, which is coincident with a sudden drop in flame base height during upstream propagation process. Thus, further analysis of the variation of absolute flame speed with the axial location could provide more information on the interaction between propagating flame edge and corona discharge.

The dynamic response of flame base motion with respect to PRF can be explained further by determining the leading-edge flame propagation speed at the various instants in a discharge sequence. According to the measurements of $V_{F}$ and $V_{g}$ at the conditioned flame base corresponding to various instants, the $S e$ can be estimated and plotted versus 
the axial location in Figure 4. Based on experimental results conducted by several previous studies, the mean $S e$ is estimated to fall within the range of $0.7 S_{L}$ to $1.2 S_{L}$, where $S_{L}$ is the corresponding laminar flame velocity, with the jet exit Reynolds number up to 8500 [19], and it will be augmented to $3 S_{L}$ due to turbulence effect as Reynolds number is increased to 15,000 [20]. The result shows that the majority of $S e$ at the pulse instant for $200 \mathrm{~Hz}$ case is larger than that of the instant between pulses and is beyond $1.2 S_{L}$ as compared with the natural lifted flame having a similar range of Re number. It suggests that the effect of pulse electric discharges on flame intensity is more significant at the pulse instant during the forced propagation process. After initiation of corona discharges the Se is still less than 3 $S_{L}$, ranging from $1.9 S_{L}$ to $2.4 S_{L}$ at the pulse instant, leading to the above findings that the flame base height is maintained at the axial location of $4 \mathrm{~mm}$ by repetitive pulsed corona discharges for low PRF cases. For high PRF of $600 \mathrm{~Hz}$ case, there is a slight difference in the level of $S e$ between various instants before initiating corona discharges, but after initiation of corona discharges at the height of about $6.5 \mathrm{~mm}$ the $S e$ is seen to augment over the $3 S_{L}$ level at the pulse instant and the flame-edge is found to travel upstream beyond the $4 \mathrm{~mm}$ location to stabilize and relocate near the nozzle exit, leading to forced reattachment. The overall Se at the instant between pulses for $600 \mathrm{~Hz}$ case is larger than that of $200 \mathrm{~Hz}$ case along all the axial locations, apparently exceeds $1.2 S_{L}$ so that the flame base can propagate more rapidly. Upon observing dynamic response of flame base to different pulse-to-pulse durations, it can be comprehensively conceived that having repetitive pulse electric discharges in the shorter duration could generate the synergistic effect between pulses and enhance Se during forced propagation process.
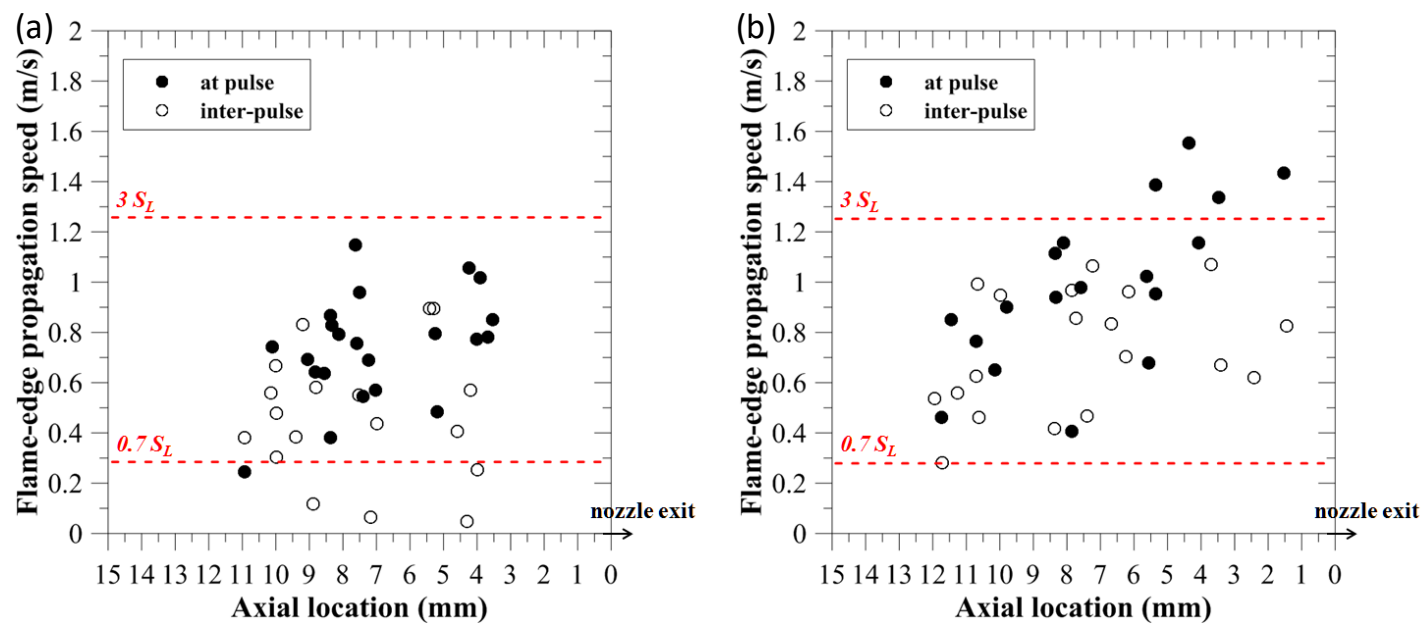

Figure 4. Variation of conditionally instantaneous flame-edge propagation speed at the different instants with the axial location for various PRF case: (a) $200 \mathrm{~Hz}$ (b) $600 \mathrm{~Hz}$.

\subsection{D Ozone Density Distribution}

Figure 5 shows the ensemble-averaged qualitative ozone number density contours for two different measurement regions at specific delay times from the initiation of pulsed discharges for PRF of $200 \mathrm{~Hz}$ case. The intensity of each image is based on the same exposure time of ICCD camera. The constant contours are labeled with the same ozone density level for the same measurement region under individual PRF condition. In addition, the stoichiometric concentration contour represented by green dashed line is also depicted on the plot for comparison with the flame base trace (red dashed line line) during the forced propagation process. It is anticipated that the instantaneous flame base will propagate into the measurement zone of $Z=2.3-4.7 \mathrm{~mm}$, indicated by $Z=3.5 \mathrm{~mm}$ and just anchors at the axial location of about $4 \mathrm{~mm}$. It shows that the ozone density level on the path of forced flame propagation has reduced to a lower value as compared with previous temporal distributions, and there exists a decay of ozone density in the lower measurement 
zone of $Z=-0.7-1.7 \mathrm{~mm}$, around the electrode-tip for $Z=0.5 \mathrm{~mm}$ region. Moreover, the data of flame-edge propagation speed at specific axial locations can be used to verify the combustion enhancement effect by ozone. In Figure $4 \mathrm{a}$, the flame propagation speeds at axial location near $4 \mathrm{~mm}$ for the case of pulse instant are in a range of $1.9 S_{L}$ to $2.4 S_{L}$. Apparently, the forced propagation path distributes along the lower ozone density region, indicating that the enhancement effect is moderate and minor.

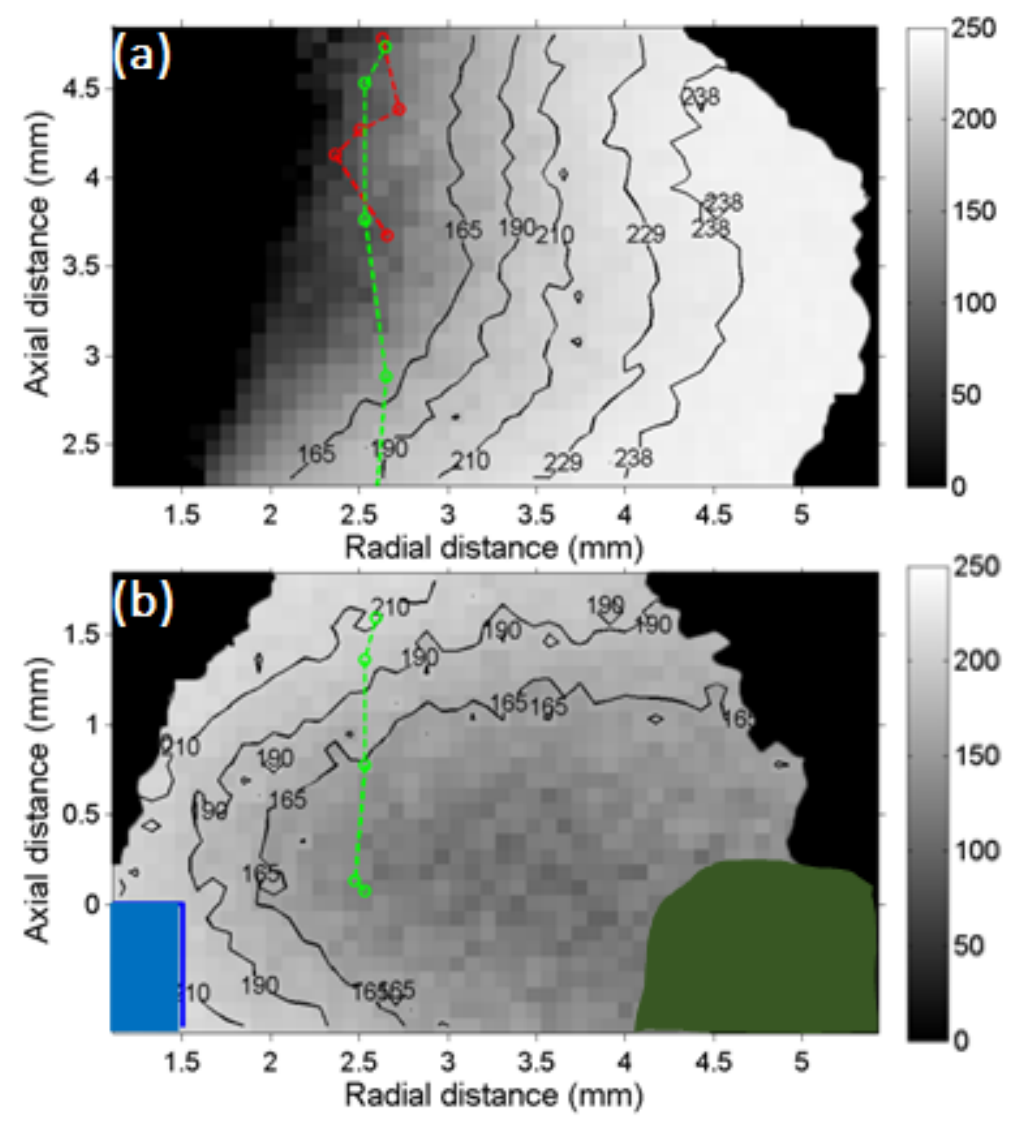

Figure 5. Contour plot of qualitative ozone number density distribution with respect to jet exit center ( $R=0 \mathrm{~mm}, Z=0 \mathrm{~mm}$ ) at $350 \mathrm{~ms}$ of delay times after initiation of pulsed discharges for PRF of $200 \mathrm{~Hz}$ case. $(\mathbf{a}, \mathbf{b})$ respectively show the measurement region of $Z=3.5 \mathrm{~mm}(2.3-4.7 \mathrm{~mm})$ and $Z=0.5 \mathrm{~mm}$ ( $-0.7-1.7 \mathrm{~mm})$. The green dashed line: stoichiometric concentration contour; Red dashed line: forced propagation flame-edge trace. Intensity bar represented by arbitrary unit.

Figure 6 shows the averaged qualitative ozone density contour of the lower measurement zone distribution at $Z=0.5 \mathrm{~mm}$ region for PRF of $200 \mathrm{~Hz}$ and $600 \mathrm{~Hz}$ cases. The results indicate that the ozone density distribution decays during $500 \mathrm{~ms}$ to $502.5 \mathrm{~ms}$ for PRF of $200 \mathrm{~Hz}$ case. In that time period, the ozone density appearing around the stoichiometric contour reduces to a lower level. As for PRF of $600 \mathrm{~Hz}$ case, the ozone distribution moves left side near the nozzle rim during $70 \mathrm{~ms}$ to $70.8 \mathrm{~ms}$, resulting in higher ozone density on the left side of stoichiometric contour than on the right. It implies that the ozone molecules will probably accumulate in the fuel-rich region and is transport downstream so as to form the high-density channel. Similarly, the axial and radial locations extracted from the data of flame propagation speed at the axial location near $1.5 \mathrm{~mm}$ as shown in Figure $4 \mathrm{~b}$ are also marked on Figure $6 \mathrm{~b}$ by star symbols. It is found that the conditioned flame-base at pulse and interpulse instants have the propagation speed of 3.3 and $2.1 S_{L}$ respectively, which both appears in the high ozone density region in Figure $6 \mathrm{~b}$. Therefore, the enhancement effect of ozone can be conceived. As shown in Figures 5 and 6 of the ozone density, contour is typically around the value of 120-220. 

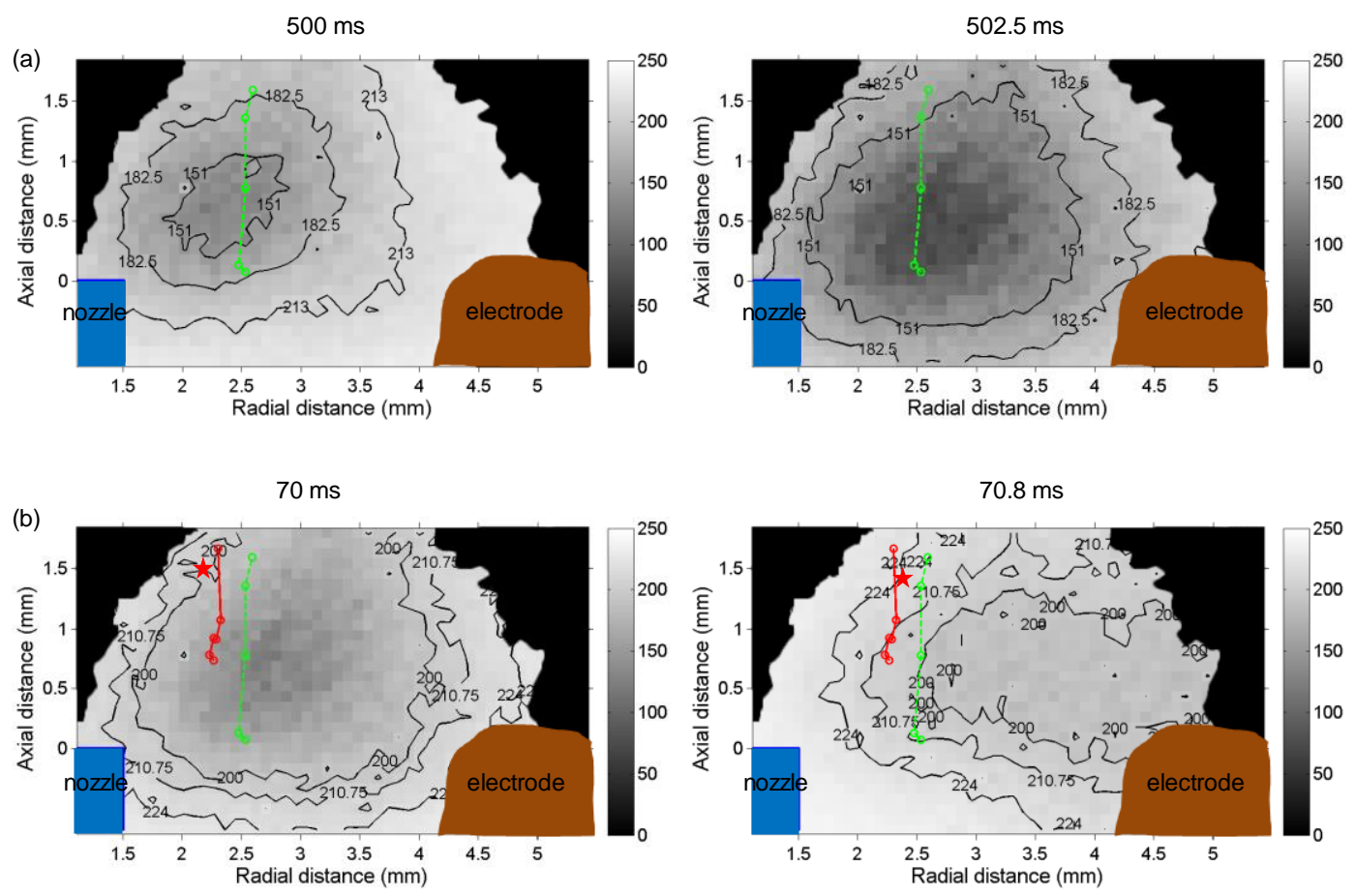

Figure 6. Contour plot of averaged qualitative ozone density distribution with respect to jet exit center $(\mathrm{R}=0 \mathrm{~mm}, \mathrm{Z}=0 \mathrm{~mm})$ at specific delay times after discharge initiation for various PRF cases: (a) $200 \mathrm{~Hz}$ (b) $600 \mathrm{~Hz}$. Dashed line: stoichiometric contour; Bold solid line: forced propagation trace of flame base. Intensity bar represented by arbitrary unit. Star symbols represent the data acquired from Figure $5 b$.

\subsection{The Reattachment Mechanisms}

Based upon the above results and findings, a novel forced reattachment mechanism is proposed: initially, the stabilization points of lifted flame-base anchors at a specific axial location with the dynamic balance between local flow velocity and flame propagation speed along the stoichiometric contour (Figure 7a). After pulse discharge and prior to corona initiation (Figure $7 \mathrm{~b}$ ), the ozone molecules could be produced by electric pulsed discharges and entrained to the shear layer of jet flow, where they are mixed up with incoming fresh combustible mixture. The leading-edge of flame-base within the shear layer can propagate upstream immediately along the stoichiometric contour at the pulse instants when the mixture with a few ozone molecules reaches to the flame front. As the flame-edge propagates farther to the location close to the electrode, the corona plasma is initiated and produces more ozone molecules around the electrode, which are immediately advected to the flame front by flow, leading to the increase in $S e$, as a result, the flame-edge starts acceleration along the stoichiometric contour (Figure 7c). At this stage, the majority of ozone molecules are distributed to the periphery of jet flow, thus, it is conjectured reasonably that the ozone density around the stoichiometric contour would attain the higher level in the far downstream region than that of measured zone of $Z=3.5 \mathrm{~mm}$ due to fuel concentration expansion.

At the corona enhancement stage, the enhancement mechanism is related to the ozone density distribution, which is influenced by repetitive corona discharges at the various PRF. For the PRF lower than $600 \mathrm{~Hz}$ cases (Figure 7d), the flame-edge anchors at the more upstream location above the nozzle exit after propagation. Ozone can become a carrier of atomic oxygen and can be certainly transported to flame front at low temperature below $400 \mathrm{~K}$. Previous literature [14] indicated that the ozone molecules will decompose immediately early in the preheat zone of flame and release $\mathrm{O}$ and $\mathrm{O}_{2}$ :

$$
\mathrm{O}_{3}+\mathrm{hf}_{(240-310 \mathrm{~nm})} \rightarrow \mathrm{O}_{2}+\mathrm{O}
$$




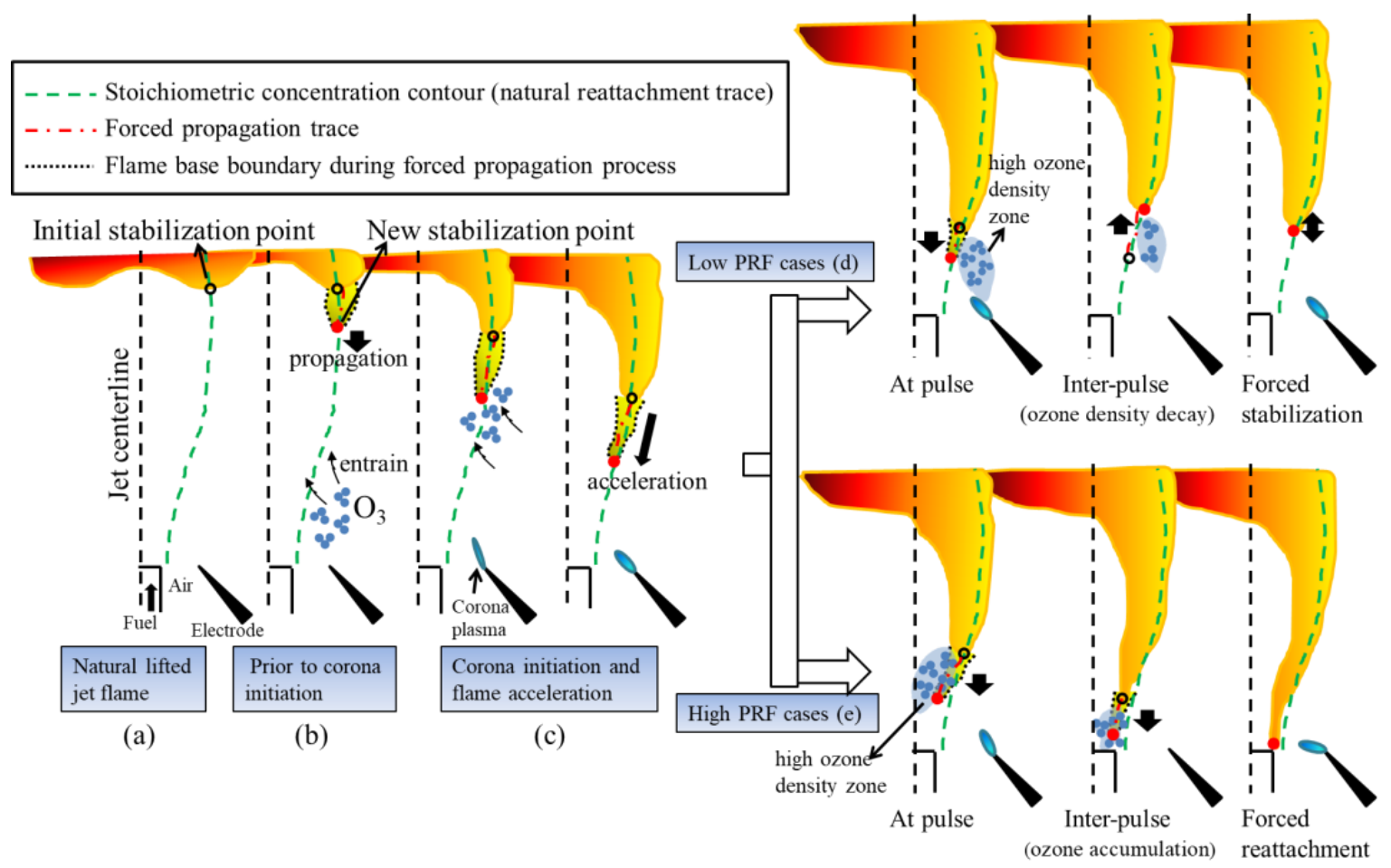

Figure 7. Schematics of the proposed forced stabilization and reattachment process mechanism.

Then atomic oxygen rapidly reacts with the fuel to abstract an $\mathrm{H}$ atom, also, the ozone simultaneously reacts with $\mathrm{H}$ atom, both leading to produce abounding $\mathrm{OH}$. Following these $\mathrm{OH}$ molecules react with the fuel and fuel fragments to form $\mathrm{H}_{2} \mathrm{O}$ and produce heat release early in the preheat zone, leading to temperature augmentation. According to the results of ozone density distribution in the corona enhancement stage, the considerable ozone molecules still accumulate in the region located on the right side of stoichiometric contour. The high ozone density zone is produced repetitively at the pulse instant, but it significantly decays in the interpulse period, which directly affects the Se at the flame edge, resulting in the flame dynamic response to different discharge instants. Eventually, the flame-edge pulsates along the stoichiometric contour and is stabilized forcibly by corona discharges. As for the PRF larger than $600 \mathrm{~Hz}$ cases (Figure 7e), the ozone density distribution in upstream of flame-edge is unlike that of the lower PRF cases due to the synergistic effect of pulsed corona discharges. The high ozone density zone appears in the narrow region located on the left side of stoichiometric contour in upstream of flame-base. Thus, according to the kinetic enhancement effect of ozone, the $S e$ of flame-edge toward the direction normal to the high ozone density zone is significantly enhanced over $3 S_{L}$ at the pulse instant, leading to flame reattachment to burner rim. It implies that the stabilization point of triple flame would be changed from stoichiometric concentration region to fuel-rich region accompanying with a considerable flame-edge propagation speed which is beyond the theoretically predicted triple flame speed of $2.6 S_{L}$ in the limit of zero mixture fraction gradient [21].

\section{Conclusions}

The enhanced reattachment behaviors and forced propagation process of a turbulent lifted propane-jet diffusion flame by a repetitive DC pulsed discharge with a proposed single-electrode configuration have been experimentally investigated in this study. The DC pulsed discharge of positive polarity with the PRF ranged from $200 \mathrm{~Hz}$ to $1500 \mathrm{~Hz}$ can effectively reduce the lift-off height, and the flame base can be reattached to the nozzle rim when the PRF is beyond $600 \mathrm{~Hz}$. It is also found that the flame-edge propagation speed along the axial location is enhanced at the pulse instant but is moderated during the 
interpulse period for $200 \mathrm{~Hz}$ case; nevertheless, it is unvaried during the interpulse period for $600 \mathrm{~Hz}$ case, after initiation of repetitive pulsed discharges. In addition, applying highvoltage positive pulse to the electrode-tip can produce ozone molecules. At the interpulse instant, the ozone density decays for $200 \mathrm{~Hz}$ case but is maintained for $600 \mathrm{~Hz}$ case. This synergistic effect of increasing PRF will significantly influence the temporal variation of ozone density distribution in far upstream of flame base, leading to the variation in flame propagation tracing, as compared with the stoichiometric contour represented by the trace of natural reattachment process.

A novel reattachment mechanism is proposed to describe the forced propagation process with various PRFs. The physical mechanism is based on the enhancement effect of corona-produced $\mathrm{O}_{3}$ on flame-edge propagation speed. Initially, the original leadingedge flame propagates upstream along the stoichiometric contour with the propagation speed enhancement by $\mathrm{O}_{3}$ addition. Prior to initiation of corona discharge, the change in flame structure by $\mathrm{O}_{3}$ is insignificant. In the corona initiation stage, more production of ozone induces the triple flame to accelerate propagation along the stoichiometric contour, followed in corona enhancement stage by the synergistic effect of ozone accumulation caused by increasing PRF of corona discharge which could modify the flame structure, shifting the flame-edge to fuel-rich concentration region together with the enhancement propagation speed which is beyond the theoretical triple flame speed. According to the measurements of gas velocity distribution at the flame base, it implies that the chemical heat release early, just ahead of flame-edge by $\mathrm{O}_{3}$ addition, could create a flow field dilution at the flame base, which is suitable for flame reattachment.

Author Contributions: Conceptualization, T.-W.C.; methodology, T.-W.C.; software, T.-W.C.; formal analysis and investigation, T.-W.C.; writing—original draft preparation, T.-W.C.; writing-review and editing, Y.-P.C.; supervision, Y.-C.C.; project administration, Y.-C.C.; funding acquisition, Y.-C.C. All authors have read and agreed to the published version of the manuscript.

Funding: This paper was supported by the Ministry of Science and Technology (MOST) and funded by the Taiwan government (NSC 102-2221-E-006-080-MY3).

Institutional Review Board Statement: Not applicable.

Informed Consent Statement: Not applicable.

Data Availability Statement: Not necessary or applicable because no additional data or supplementary data is associated with this paper.

Acknowledgments: This paper was supported by the Ministry of Science and Technology (MOST) and funded by the Taiwan government. We gratefully acknowledge their support.

Conflicts of Interest: The authors declared that they have no conflict of interest to this work.

\section{References}

1. Weinberg, F.J. Advanced Combustion Method; Academic Press: London, UK, 1986; pp. 332-394.

2. Rickard, M.; Dunn-Rankin, D.; Weinberg, F.; Carleton, F. Characterization of ionic wind velocity. J. Electrost. 2005, 63, 711-716. [CrossRef]

3. Zake, M.; Barmina, I.; Turlajs, D. Electric field control of polluting emissions from a propane flame. Glob. Nest Int. J. 2001, 3, 95-108.

4. Ju, Y.; Sun, W. Plasma assisted combustion: Progress, challenges, and opportunities. Combust. Flame 2015, 162, 529-532. [CrossRef]

5. Altendorfner, F.; Kuhl, J.; Zigan, L.; Leipertz, A. Proc. Study of the influence of electric fields on flames using planar LIF and PIV techniques. Proc. Combust. Inst. 2011, 33, 3195-3201. [CrossRef]

6. Cessou, A.; Varea, E.; Criner, K.; Godard, G.; Vervisch, P. Simultaneous measurements of OH, mixture fraction and velocity fields to investigate flame stabilization enhancement by electric field. Exp. Fluids 2012, 52, 905-917. [CrossRef]

7. Starikovskii, A.Y. Plasma supported combustion. Proc. Combust. Inst. 2005, 30, 2405-2417. [CrossRef]

8. Bradley, D.; Nasser, S.H. Electrical coronas and burner flame stability. Combust. Flame 1984, 55, 53-58. [CrossRef]

9. Pilla, G.; Galley, D.; Lacoste, D.A.; Lacas, F.; Veynante, D.; Laux, C.O. Stabilization of a turbulent premixed flame using a nanosecond repetitively pulsed plasma. IEEE Trans. Plasma Sci. 2006, 34, 2471-2477. [CrossRef]

10. Vincent-Randonnier, A.; Larigaldie, S.; Magre, P.; Sabel'nikov, V. Plasma assisted combustion: Effect of a coaxial DBD on a methane diffusion flame. Plasma Sources Sci. Technol. 2007, 16, 149-160. [CrossRef] 
11. Criner, K.; Cessou, A.; Louiche, J.; Vervisch, P. Stabilization of turbulent lifted jet flames assisted by pulsed high voltage discharge. Combust. Flame 2006, 144, 422-425. [CrossRef]

12. Kim, W.; Do, H.; Mungal, M.G.; Cappelli, M.A. Plasma-discharge stabilization of jet diffusion flames. IEEE Trans. Plasma Sci. 2006, 34, 2545-2551. [CrossRef]

13. Samaranayake, W.J.M.; Miyahara, Y.; Namihira, T.; Katsuki, S.; Sakugawa, T.; Akiyama, R.H.H. Pulsed streamer discharge characteristics of ozone production in dry air. IEEE Trans. Dielect. Electr. Insul. 2000, 7, 254-260. [CrossRef]

14. Wang, Z.H.; Yang, L.; Li, B.; Li, Z.S.; Sun, Z.W.; Alden, A.; Cen, K.F.; Konnov, A.A. Investigation of combustion enhancement by ozone additive in $\mathrm{CH} 4$ / air flames using direct laminar burning velocity measurements and kinetic simulations. Combust. Flame 2012, 159, 120-129. [CrossRef]

15. Ombrello, T.; Won, S.H.; Ju, Y.; Williams, S. Flame propagation enhancement by plasma excitation of oxygen. Part I: Effects of $\mathrm{O}_{3}$. Combust. Flame 2010, 157, 1906-1915. [CrossRef]

16. Chang, T.-W.; Chao, Y.-C.; Cheng, T.-S. Experimental investigation of reattachment behavior of turbulent lifted diffusion jet flames induced by repetitive DC electric pulse discharges with conditional PIV. Combust. Sci. Technol. 2019, 191, 726-744. [CrossRef]

17. Ono, R.; Oda, T. Spatial distribution of ozone density in pulsed corona discharges observed by two-dimensional laser absorption method. J. Phys. D Appl. Phys. 2004, 37, 730-735. [CrossRef]

18. Ono, R.; Oda, T. Ozone production process in pulsed positive dielectric barrier discharge. J. Phys. D Appl. Phys. 2007, 40, 176-182. [CrossRef]

19. Upatnieks, A.; Driscoll, J.F.; Rasmussen, C.C.; Ceccio, S.L. Liftoff of turbulent jet flames-Assessment of edge flame and other concepts using cinema-PIV. Combust. Flame 2004, 138, 259-272. [CrossRef]

20. Gordon, R.L.; Boxx, I.; Carter, C.; Dreizler, A.; Meier, W. Lifted diffusion flame stabilisation: Conditional analysis of multiparameter high-repetition rate diagnostics at the flame base. Flow Turbul. Combust. 2012, 88, 503-527. [CrossRef]

21. Ruetsch, G.R.; Vervisch, L.; Liñán, A. Effects of heat release on triple flames. Phys. Fluids 1995, 7, 1447-1454. [CrossRef] 